\title{
Volition versus feasibility: state aid when aid is looked upon favourably: the broadband example
}

\author{
José Luis Gómez-Barroso · Claudio Feijóo
}

\begin{abstract}
The European Commission published on September 30, 2009, Guidelines for the application of State aid rules in relation to rapid deployment of broadband networks. These Guidelines are applicable to two markets that are connected, although somewhat different. In "traditional" or "first generation" broadband networks, public intervention mainly relates to rural communities or areas which are economically underdeveloped. Therefore, a corrective nature of the aid is maintained. However, the Guidelines are also applied to accelerate the deployment of next-generation access (NGA) networks, which implies a driving conception of State aid, as this is an emerging market and there are relatively few Europeans who have access to these networks. The analysis of these Guidelines thus seems relevant due to its novelty and, particularly, to the results that it can bring.
\end{abstract}

Keywords Broadband - Market failures - Next-generation access networks · Public funds - State aid - Telecommunications

JEL Classification $\mathrm{H} 540 \cdot \mathrm{K} 230 \cdot \mathrm{L} 960$

\footnotetext{
J. L, Gómex-Barroso

Dpto. Economía Aplicada e Historia Económica, UNED, Universidad Nacional de Educación a Distancia, $\mathrm{P}^{\circ}$ Senda del Rey, 11, 28040 Madrid, Spain

e-mail; jlgomez@cee.uned,es

C. Feijóo

Campus de Montegancedo, CeDInt, Universidad Politécnica de Madrid, 28223 Pozuelo de Alarcón, Madrid, Spain e-mail: cfeijoo
} 


\section{Introduction}

In June 2005, the European Commission presented and then submitted to public consultation its State Aid Action Plan (European Commission 2005). The title announced its basic objective: "less and better targeted State aid". Among the reforms of the process, one of the most important indicated that "the Commission will, when relevant, strengthen its economic approach to State aid analysis".

This strengthened economic approach is the determination of a series of criteria used to assess the compatibility of the aids. starting in all cases with the identification of the "market failure" that justifies the granting of the aid. This identification "will help evaluate better whether State aid could be justified and acceptable. would represent the most appropriate solution, and how it should be implemented to achieve the desired objective without distorting competition and trade to an extent concrary to the common interest".

The plan itself puts forward some of these "market failures", defined as sinations where the market does not lead to an economically efficient outcome: the existence of externalities, public goods. imperfect information. coordination problems and market power. The list is not comprehensive and does not include some of the most important motives for a public intervention, such as undeveloped markets (lack of supply of the good in certain areas or situations) or social considerations.

Additionally, public intervention is frequently based not on one but on the combination of some of these causes; intervention is carried out. for example. in incomplete markets or markets with competition problems. but in any case. it is carried out in markets of goods or services that show characteristics that advise for public intervention (extenualities. goods defined as "merit goods"). This is precisely the typical sinuation that, with or without prior analysis, has covered the State aids applied to specific sectors of economic activity; the aids have been addressed to correct specific problems in "particular", though manure. markets. As a major example, this has been the case of the aids targeted towards the deployment of infrastructures and, more specifically, to that of the telecommunication networks. In this sector, the corrective usage of public funds has generally dominated; the aid has been addressed to areas that had proven not to be profitable for the operators (rural communities or areas with low economic development).

The use of the past tense ("has been the case") is explained by the novelty introduced by the Guidelines for the application of State aid rules in relation to the rapid deployment of broadband networks that the European Commission published on September 30, 2009. Despite the single title, these Guidelines are applicable to two markets that are connected, although somewhat different. On the one hand. "traditional" or "first generation" broadband networks (both terms are used in the Guidelines), for which the corrective nature of the aid is maintained. On the other hand. the Guidelines are also applied to accelerate the deployment of nextgeneration access (NGA) networks, ${ }^{1}$ which implies a driving conception of State

\footnotetext{
${ }^{1}$ According to the Guidelines. NGA networks are "wired access networks which consist wholly or in part of optical elements and which are capable of delivering broadband access services with enhanced characteristics (such as higher hroughput) as compared to those provided over existing copper networks".
} 
aid, as this is an emerging market, and there are relatively few Europeans who have access to these networks.

Undoubcedly, this latter fact is hugely important. First, it is conceptually important because the order of the causes that motivate the intervention is changed. In a corrective conception, it is the market situation that takes precedence. On the contrary, the driving conception is based on the "importance of the good". although it is obvious that the measure taken must adapt to the market reality. Second, it is also significant (or could be if the member States were to use this option to a great extent), from a quantitative perspective. It is not difficult to presume that the amount required for aid intended to make next-generation broadband access universal would be much greater than that given to projects involving "traditional" broadband.

The analysis of these Guidelines thus seems relevant due to its novelty and. particularly, to the resules that it can bring. Additionally, the Guidelines also develop a particular "area-based balancing test". an issue of interest, which can be also adapted to other sectors.

This article starts by describing the Guidelines before providing a critical assessment on their foundation. their possible benefits and risks and the problems that their practical implementation could entail. The conclusions are presented at the end of the paper.

\section{Analysis of the Community Guidelines for the allocation of public funds to broadband networks}

Despite the fact that the title of the Guidelines specifically refers to "the application of the rules on State aids". the truth is that their contents describe in detail different procedures for public funding. which are not exclusively limited to State aid in a strict sense (see Fig. 1).

\subsection{Use of public funds that do not constinte State aid}

\subsubsection{Investment}

Following the principle of equal treatment (and according to the case-law of the Court of Juscice of the European Communities), the Guidelines establish that capital placed by the State. directly or indirectly, at the disposal of an undertaking "in circumstances which correspond to normal market conditions" cannot be regarded as State aid.

The conformity of a public investment with the application of the "market economy investor principle" has to be demonstrated by the following means:

- The existence of a sound business plan showing an adequate return on investment.

- Significant participation of private investors who take part in the project and assume the commercial risk linked to the investment under the same terms and conditions as the public investor. 


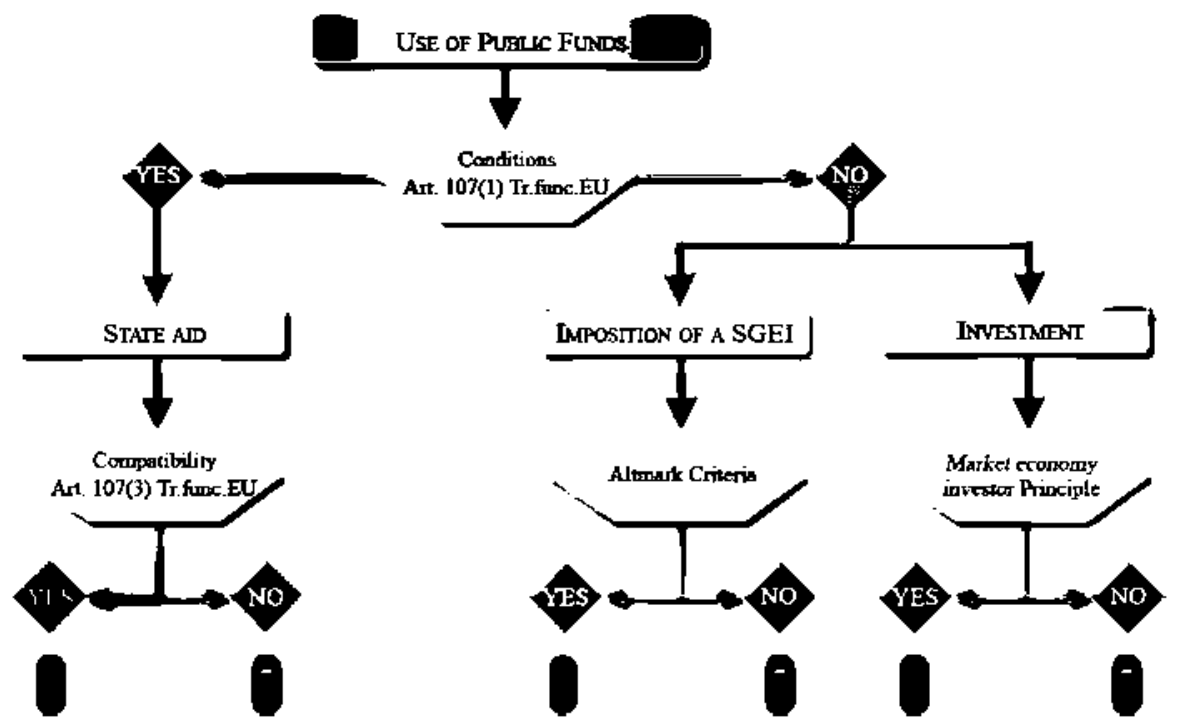

Fig. 1 Possible channels for the use of public funds

No distinction is established between "tradicional" and "new" broadband networks. The conditions are identical in both cases.

\subsubsection{Imposition of a service of a general economic interest (SGEI) mission}

The determination of the nature and scope of an SGEl mission falls within the competence and discretionary powers of Member States. However, such competence is "neither unlimited nor can it be exercised arbitrarily". which, in the case of broadband networks, means that "in areas where private investors have already invested in a broadband network infrastructure (or are in the process of expanding further their network infrascructure) and are already providing comperitive broadband services with an adequate broadband coverage, setting up a parallel competitive and publicly funded broadband infrastrucnure should not be considered as an SGEI".

However, a public service compensation may be granted to an underaking encnusted with the operation of an SGEI on the condition that it can be demonstrated that private investors may not be in a position to provide adequate broadband coverage to all citizens or users in the "near future" (understood as referring to a period of 3 years).

According to the case-law of the Court. State funding for the provision of an SGEI may not be regarded as State aid, provided that four conditions are met. Those conditions are commonly referred to as "the Almark criteria":

a) the beneficiary of a State funding mechanism for an SGEI must be formally entrusted with the provision and discharge of an SGEI, the obligations of which must be clearly defined 
b) the parameters for calculating the compensation must be established beforehand in an objective and cransparent manner

c) the compensation cannot exceed what is necessary to cover all or part of the costs incurred in the discharge of the SGEI, taking into account the relevant receipts and a reasonable profit

d) where the beneficiary is not chosen pursuant to a public procurement procedure. the level of compensation granted must be detenmined on the basis of an analysis of the costs that a typical "well-run" undertaking would have incurred

The first of the criteria demands "clearly defined obligations". In the deployment of broadband networks, there are at least two obligations: to connect all cirizens and businesses, and to make the network available for all interested operators, allowing effective competition at the retail level (the publicly funded network should be a passive. neutral and open-access infrastructure).

No distinction is established here between both types of broadband networks, either. Because nothing is specified, it can be understood that the interpretation of the "near future" is also 3 years for the NGA networks.

\subsection{3 "Other alternatives"}

These ocher altenatives are specifically mentioned in the case of the NGA networks, although there are no obstacles to their use in the case of traditional broadband.

Member States may decide to adopt a set of measures to accelerate the investment cycle and, thus, encourage investors to advance their investment plans. Specifically, this consists of carrying out civil works. Indeed, a large part of the cost of deploying telecommunication networks (particularly fibre networks) is incurred in digging, laying down cables or installing in-house wiring. In this respect. Member States may decide. for instance, to undertake some works such as digging of the public domain. or construction of ducts. For this practice to be admissible, such civil works should not be "industry or sector specific" but should be open to all potential users and not just electronic communications operators (e.g. electricity, gas or water utilities).

The Guidelines also mention options such as easing the acquisition process of rights of ways or demanding that network operators coordinate their civil works and/or share part of their infrastructure. Note. however, that these are regulatory measures that do not require any public funds to be paid out.

\subsection{State aid}

A part of the aids granted for the deployment of broadband networks could be considered to be included in the exception stated in item a) of article 107, section 3. of the Treaty on the functioning of the European Union" ("aid to promote the

\footnotetext{
${ }^{2}$ Previous to December 1.2009, the date on which the Lisbon Treaty entered into force. it was article 87 of the Trealy establishing the European Community. Most doctrines and studies refer, then, to "article $87^{\prime \prime}$.
} 
economic development of areas where the standard of living is abnormally low or where there is serious underemployment"). However, it is item c) of this section that makes generally acceptable the aid granted by the States for these projects ("aid to facilitate the development of certain economic activities or of certain economic areas, where such aid does not adversely affect trading conditions to an extent contrary to the common interest").

According to the State Aid Action Plan (European Commission 2005), in assessing whether any specific measure can be deemed compatible with the common market, the Commission must first identify the market failure at stake and then must apply a so-called "balancing test". comparing the positive impact of the aid with its potential negative side effects.

Regarding the first requirement, the Guidelines indicate that aid for broadband network deployment can correct situations where individual market players do not invest (even though this would be efficient from a wider economic perspective) and may also be viewed as a tool to achieve equity objectives ("a way to improve access to an essential means of communication and participation in society as well as freedom of expression to all actors in society, thereby improving social and territorial cohesion").

Next. the application of the "balancing test" considers both the negative effects of aid on competition and its positive effects in temns of common interest. According to paragraph 20 of the Action Plan, the positive impact of aid depends, in general, on the following questions: (1) how accurately the accepted objective of common incerest (whether social, regional, economic or cultural) has been identified; (2) whecher Stace aid is an appropriate instrument as opposed to other policy instruments for dealing with the problem, and (3) whether the aid creates the needed incentives and is proportionate. On the other hand, the level of distortion created by an aid generally depends on the following factors: (1) the procedure for selecting beneficiaries and the conditions attached to the aid: (2) characteristics of the market and of the beneficiary, and (3) the amount and type of aid.

The Guidelines for the broadband aids set out a similar theoretical background but specify it in a "coloured area" analysis:

- "White" areas are those where broadband is currently not available and where there are no plans by private investors to roll out such an infrastructure in the near future.

The term "in the near future" should be understood as referring to a period of 3 years (both for traditional and NGA broadband networks). In this regard. investment efforts planned by private investors should not guarantee that significant progress in terms of coverage will be made within the three-year period (with completion of the planned investment foreseen within a reasonable time frame thereafter).

In the Guidelines it is recognised that the Commission has taken an overwhelmingly fovourable view towards State measures for broadband deployment for underserved, typically rural, areas.

- "Grey" areas are those where only one broadband network operator is present. 
In these situations. State support for the deployment of broadband networks calls for "a more detailed analysis and careful compatibility assessment" (as monopoly provision "may affect the quality of service or the price at which services are offered to the citizens". but. on the other hand, subsidies for the construction of an alternative network can distort market dynamics).

If more than one network will be deployed in the "near future" (the coming 3 years), such an area should, in principle, be considered black (see below). This precision is made only in the case of the NGA networks, although a logical analogy should make it extensible to the case of traditional broadband.

- "Black" areas are geographical zones where at least two broadband network providers are present and where broadband services are provided under competitive conditions. ${ }^{3}$

In the case of the traditional broadband. it is stated that there "is very little scope for State intervention to bring further benefits". although to do so is not specifically banned. More precisely, it is said that State support for the funding of the construction of an additional broadband network will, in principle, lead to an unacceptable distortion of competition and to the crowding out of private investors. Accordingly. "in the absence of a clearly demonstrated market failure, the Commission will view negatively" such a measure.

In black NGA areas, the wording is more specific: "no need for State intervention".

It is important to underline that if in the case of the "raditional" broadband networks, the white areas are currently the exception in the European Union. whereas in the case of the NGA networks, they are the rule. Note also that part of the areas that are grey and even black for the traditional broadband are white for the NGA networks, as there has been no deployment in these areas. For cases where there is a "change of colour". the Guidelines establish "compatibility" rules:

- In craditional grey areas (but white NGA areas), the grant of aid for NGA networks is subject to the demonstration by the Member Sate concened that "the planned NGA network is not or would not be sufficient to satisfy the needs of citizens and business users in the areas in question" (also taking into account a possible future upgrade).

- In black (basic broadband) areas no further State intervention should in principle (same clarification again) be necessary, as "existing network operators should have the incentives to upgrade their cuntent craditional broadband networks to very fast NGA networks to which they could migrate their existing customers". Member Sates can rebut such an argument "by showing that existing basic broadband operators do not plan to invest in NGA networks in the coming 3 years by demonstrating for instance that the historical pattern of the investments made by the existing network investors over the last years in upgrading their broadband infrastructures to provide higher speeds in response to users' demands was not satisfactory".

\footnotetext{
3 Therefore, facilities-based competition exists. TheTe could also exist competition al the level of services in grey areas, should the single network be open to other operators.
} 
It must be underlined that an additional qualification is made for projects to be authorised; they will be approved provided that there are no less distortive means (including ex ante regulation) to reach the scated goals.

If this requirement is met and the balancing test concludes that the overall evaluation of the project is positive. a number of fundamental conditions must be complied with to "minimise the State aid involved and the potential distortions of competition". These conditions are detailed mapping exercise and coverage analysis. open tender process, priority to the most economically advantageous offer, technological neutrality, re-use of existing infrastructure, mandated wholesale open access (for at least 7 years), benchmarking exercises (with average published or regulated wholesale prices that prevail in other comparable areas of the councry) and claw-back mechanisms (to ensure that the selected bidder is not overcompensated if the demand for broadband in the target area grows beyond ancicipated levels). In the case of NGA networks, the access obligation imposed is described with more detail. Whatever the type of the NGA network technical architecture, it should support effective and full unbundling and satisfy all different types of network access that operators may seek (including but not limited to access to ducts, fibre and the so-called "bitstream access"); in setting the conditions for wholesale network access. Member States should consult the relevant NRA.

\section{Critical evaluation of the guidelines}

\subsection{Regarding the grounds for aid granting}

The process of evaluating the compatibility of the different kinds of aid required in the 2005 Action Plan must start with the analysis of the "market failure" on which public action is based. The Guidelines tackle the issue too generally and without establishing any clear criteria. They only refer to underinvesment and equity criteria.

With more precision. Stiglitz (1988) deals comprehensively with the "causes" (market failures) that could justify State intervention on an economic activity sector and identifies up to eight (which are neither mutually exclusive nor independent). They can be regrouped into four major categories: those causes inherent to the characteristics of the good itself (public goods. merit goods and externalities); those that refer to the market situation (imperfect competition, which includes information failures and incomplete markets): macroeconomic arguments (influence in economic development); and, finally, equity reasons. Using this classification, GómezBarroso and Pérez-Martínez (2005) analyse the presence of market failures in telecommunication services, and more specifically, in the new convergent ones:

- strictly speaking. telecommunications cannot be considered a public good, although they may be considered a "mixed" good,

- there is no doubt that they provide positive externalities.

- there are sufficient arguments to include them in the merit goods group. 
- it is not clear whether the market develops conditions for competition or whether it can reach everyone, at least in the short tenm,

- they are taking on an important and growing role in economic development,

- their social relevance is high enough to apply an equity criterion.

In other words, almost all the arguments that justify State intervention can be used to a greater or lesser extent in the telecommunications domain. In fact, they are used. Each specific broadband deployment project will be backed (or should be backed) by an analysis where specific argumens take precedence over others. Therefore, the "traditional" broadband deployment in a white area would basically be backed by the market situation but accompanied by arguments of equity. On the other hand, in the deployment of NGA networks, the project should be generally backed by arguments regarding the macroeconomic effects and merit goods.

However, once this has been established. there is no criterion for classifying market failures, and it is even more difficult to deduce any specific measures. Faced with similar situations, different administrations would choose different paths. Indeed, we cannot even declare that a need for action is required; finding coverage for the intervention does not imply having to intervene. Economic theory is quite unanimous about the existence of market failures, ${ }^{4}$ but any agreement disappears when deciding how appropriate public sector intervention should be organised.

The reflection of this controversy in the political values is excremely important. Although the market economy has been accepred almost universally as the only option with which to organise economic life, it is the degree of State intervention that differentiates ideologies (could it be better to call them trends?). This leads to quite different assessments of the arguments set out in the following sections by the supporters and the detractors of the use of public funds for the deployment of broadband networks.

\subsection{Regarding the benefits associated to the action}

Almost any document related to a plan to promote the information society tries to prove the "importance of broadband" and the problems resulting from the existence of digital divides.

The Communication from the Commission entitled "Bridging the broadband gap" (European Commission 2006) offers a categorical argument: widespread broadband access is a key condition for the development of modern economies and is an important aspect of the Lisbon agenda. Additionally, it includes a section with exactly that name ("why broadband matters"), in which it develops the arguments in further detail; "The impact of broadband is just beginning to be felt. The precise impact has been difficult to measure. It is, however, clear that the ability to communicate infonnation at high speeds and through various platfonms is key to the

\footnotetext{
${ }^{4}$ The most prominent exception is the Austrian School: they point out that it is impossible to know whether or not the market is failing without an independent test, of which there is none outside the actions of indjviduals. Additionally, some authors have argued against specific market failures. Take. for example, Liebowitz and Margolis (1994) who note that "alihough network effects are pervasive in the economy, we see scant evidence of the existence of network externalities". On the other extreme, Marxists would say that all markets have inefficient and democratically-unwanted ontcomes.
} 
development of new goods and services. Broadband enables new applications and enhances the capacity of existing ones. It stimulates economic growth through the creation of new services and the opening up of new investment and jobs opportunities. But broadband also enhances the productivity of many existing processes, leading to better wages and better returns on investment."

Certainly, as declared, the impact is not easy to assess, although the academic scope has been trying to do so for decades. Among the pioneers, Saunders et al. (1983) established the relationship between communications and the growth of the services industry, which in turn was correlated with that of the GNP. This correlation between economic activity level and invesuments in telecommunications infrastructures was described by Cronin et al. (1991), Dholakia and Harlam (1994) or, more recently, Röller and Waverman (2001), using economerric techniques. However, are telecommunications the cause or the consequence of the level of development? There is a bi-directional relationship; the investment in telecommunications is a reliable predictor ("cause", the quotation marks are authors") of the subsequent economic activity level; the converse is also true (Cronin et al. 1993).

Regarding the mechanism used by telecommunications to positively influence the economy. productivity improvements and efficiency growth in markets due to the agents' being able to more swiftly answer the market signals are initially stated as basic factors (Wellenius 1984; Madden and Savage 1998). The list can be further detailed: less production coss, betcer location decisions, increased flexibility. reduced storage (and resulding capital cost) with the just-in-time production methods and an increase in competition, among orhers, can be included (Cave et al. 1994). As regards how it affecs employment, Hansen et al. (1990) found that, in six European rural areas, the impact on employment of the investment in telecommunications was between 2.2 and 5.2 times greater during the first year than at the time of the original investment.

The relationship seems clearer today in the presence of what has been called the knowledge economy, or the new economy. Telecommunications, converging with other industries towards the integration of the ICTs, act as an engine of the economy and as a source of productivity and employment and thus are universally considered as a strategic investment (between many ochers, OCDE 2003; Jalava and Pohjola 2002, 2007: Timmer and Van Ark 2005: Venturini 2009). Papers are currently being released that refer specifically to the impact of broadband (Koutroumpis 2009).

\subsection{Regarding the risks associated with the action}

\subsubsection{Impact on competition and investment}

The idea that the private sphere is superior to the public sphere, an idea that dominated the economic and political values of the late 20 th century, still prevails today despite the hesitation that seemed to appear during the most critical moments of the current crisis. The basic idea is that market forces minimise costs, regulate quality and balance supply and demand and for the other way around, that the political sector fails to allocate resources in the most beneficial manner for the general interest. The government failure theory backs this opinion: the pursuit by 
government officials of political goals and personal income as opposed to social welfare furcher strengthens the case for private ownership. "as the dismal record of state enterprises around the world and the tragedy of communism illustrate all too well" (Shleifer 1998).

Moving closer to a specific economic sector. such as the broadband market. for example, the arguments against public intervention in the supply side become more specific. Because these are well known, they do not deserve a detailed explanation: government intervention may distort competition and affect commercial incentives towards investment.

Starting with the second aspect (crowding out of investment), the analysis is quite different when it is applied to one or another type of broadband network. In traditional broadband, private operators have had time to decide what areas they were interested into deploy their networks. Obviously, this does not mean that in the future they could not reach areas that are currently "white". thus leading us to estimating what should be understood as a "reasonable period". Even more specifically, is the damage caused due to ignoring one area during the period required for the private offering going to be greater than the benefits of equipping it with the infrastructure in a relatively short period? Obviously, this balance should always be present in any public intervention and is precisely what the Guidelines propose. However, the theoretical elegance of the fonmula mees the formula's practical difficulty. Faced with the complexity (impossibility?) of quantifying exactly the pros and cons. the key to obcaining maybe not the answer, but at least a solid answer. is the evaluation of the market failures at stake ("the weight" given to each of the arguments).

If in the case of traditional broadband, there is enough ammunition to defend the argument of crowding out of private investment, in the case of the NGA, there is an entire arsenal. The percentage of fibre access in terms of the total of broadband connections represented in June 2009 , according to the OECD. was $0 \%$ in 11 of the 19 European Union countries for which data were presented!

Therefore, it is quite striking that the determination of the "near future" that conditions the use of public finds is the same for the manure traditional broadband market and for the emerging NGA network market. ${ }^{6}$ As a matter of fact, if there are no projecs for the deployment of simple networks, there will not be any for advanced networks. and this could lead all the public projecs in rural zones to directly "skip" a stage and choose the deployment of an NGA network. The reason for establishing this period of three years for the NGA networks is also explained in the Guidelines themselves: "it would not be appropriate to take a longer time horizon as this may risk damaging the interests of underserved regions relative to other parts of a country that are adequately served by such advanced broadband networks".

\footnotetext{
${ }^{5}$ Namely Finland, United Kingdom, Luxembourg, Belgium, Greece, France, Germany, Spain, Austria, Porugal and Poland. For the rest of OECD-member European Union contries, the percentages are: Ireland ( $1 \%$ ), Italy ( $3 \%$ ), Netherlands ( $3 \%$ ), Czech Republic $(5 \%)$. Hungary (6\%), Denunark (10\%) and, clearly standing out from the rest. Slovakia and Sweden (in both cases, $21 \%$.

${ }^{6}$ The period has been moditied following (or as a consequence of) the public consultation in Spring 2009 , because in the first draft, prepared in May, it was established for 5 years.
} 
However, it is not at all clear that after three years, the regions that are underserved will not continue to be a majority. The shadow of the crisis will still condition the economic scenario in the short tenm and does not seem to make it the most adequate for major investments. In one of the countries where fibre is almost starting from scratch, Spain, there exists a report about future NGA networks deployment submitted by the regulator in May 2009 (CMT-lsdefe 2009). This report estimates that if a conservative prevision is adopted. by 2023 less than $50 \%$ of the Spanish households (between 43 and $46 \%$ ) would have an optical fibre access and that the investment recovery period in cities with less than 50,000 inhabitants (should the deployment exist) would be between 13 and 14 years. If that is the 2023 scenario, what will the situation be in 2012 outside major cities?

In regards to the second reasoning. the impact on competition, deciding what type of competition is supported is essential for carrying out the assessment. This is one of the red-hot debates in the electronic communications sector; knowing whether a competition based on services, providing facilities to alternative operators in order for them to use the existing infrastructures, is preferable to a competition based on infrastructures that promotes newcomers to deploy their own networks. The first model removes the entry barriers and generates a greater number of competitors in less time. However. these competitors have fewer options for modelling their offer, making this type of competition weaker in the long-tenm. The European Commission, through iss "ladder of investment" theory, claims to have found a fonmula that allows making both models compatible, although the results have not been clearly proven yet. ${ }^{7}$

Some cime before the Guidelines were released, the debate had already moved to NGA networks. ${ }^{8}$ In this context, a neutral infrastructure, be it built with public or private funds, would provide competition in services (as soon as the network was available). Is this what is wanted for NGA networks, at least in certain areas? If the answer is not and a competition based on infrastructures is chosen instead. the impact of a public network on the development of private infrastructures would be unquestionable and probably quite lengthy.

\subsubsection{Inhibition of the technological development}

Although this is connected to issues set forth in the section above, characterising this specific problem is worth the effort; by picking particular technologies. technological development may be inhibited.

\footnotetext{
7 Note to this regard that in the new elecironic communications framework. vertical (functional) separation is accepted as a solution to eliminate persistent competition problems. This is a recognition that at least in some markets, the existence of more than one network could be not possible.

${ }^{8}$ The maller is complex enough for the Commission to have launched two consecutive public consultations on both drafts dealing with the regulation that should be applied to the NGA networks. The public consultations took place in Autumn 2008 and Summer 2009. The definitive Communication has not yet been published. That the NGA networks will be subject to regulation seems unquestionable (dismissing the "regulatory holidays" requested by some incumbent operators and even granted initially by the German regulator). The specitic details of that regulation will indeed tilt the scales towards one or another type of competition.
} 
Indeed, this is not the case with traditional broadband, where the Guidelines establish technological neutrality. However, in the case of the NGA, a specific definition is given; they are cabled networks. ${ }^{9}$ In a footnote, it is staced that "at this stage of technological and market development, neither satellite nor mobile network technologies appear to be capable of providing very high speed symmetrical broadband services although in the future the situation may change especially with regard to mobile services (the next major step in mobile radio communications. 'Long Term Evolution' may theoretically reach. if and when adopted, increased peak data rates of 100 Mbps downlink and 50 Mbps uplink)".

However, among many references along the same lines, a document prepared by the consultancy finm Analysis for the UMTS Forum (Analysys 2008) states that LTE is likely to gain a strong foothold in the market by 2013 and forecasts that the LTE subscriber base will reach 437 million by 2015, with Western Europe contributing 150 million of this amount. More important than the simple expectations or forecasts is that the barriers do not seem to be technical ${ }^{10}$ and are not even related to the deployment cost. ${ }^{11}$ Specifically, in the opinion of the consultancy firm. the truly critical factor is the confidence of the mobile communication operators in the fact that the improved quality of the services that LTE will allow to offer will translate into an increased ARPU (average revenue per user). Undeniably, this is an important clarification, although it is not different than the one set out for the fixed communications operators when faced with the transition to fibre of their "firstgeneration" broadband networks.

A GSA (Global mobile Suppliers Association) ${ }^{12}$ document provides more specific data on the deployment of LTE. Here, it is stated that there were 39 LTE network commitments in 19 countries in August 2009. 14 LTE networks will be in service by the end of 2010 and 31 LTE networks will be in service by the end of $2012{ }^{13}$ It is also stated that terminals will be available very soon.

\footnotetext{
${ }^{9}$ The first draft, made on May 2009, provided a much more precise definition, which even differentiated cabled buildings and new constructions. NGA networks were detined as follows: (1) networks with fibre reaching the existing street calbinets offering the prospects of downsiream bandwidths of a mininum of 40 and 15 Mbps upstream: (2) cable networks delivering speeds up to and beyond $50 \mathrm{Mbps}$ thanks to the DOCSIS 3.0 standard; or (3) fibre connections in new constructions with speeds above $100 \mathrm{Mbps}$.

${ }^{10}$ It is said that technical specitications for LTE are now stabilised within the Third Generation Parnersing Project-3GPP. Looking further into the fulure, there are plans for wireless solutions different from LTE that would supply data rates approaching 1 Gbps (Ramos et al. 2009).

${ }^{11}$ In a survey among industry managers, opinions about the cost of moving from a $3 \mathrm{G}$ network to an LTE network were divided. with around just under half of those asked expecting the cost to be comparable to the inigration from $2 \mathrm{G}$ to $3 \mathrm{G}$, with the remainder expecting costs to be closer to those involved in moving from a 3G network to an HSPA network. Both costs seemed acceptable before the fact, as the mobile communications opetators are carrying out this progressive evolution of "mobile generations". This is provided. naturally, as stated in the main text. that there exists a demand that makes it feasible.

${ }^{12}$ http:/www.Iteforum2009.com/repor/GSA\%20Information\%20Papex\%20LTE_260809.pdf.

${ }^{13}$ In Europe, 2010 is mentioned as the date for the commissioning of networks in Sweden (three: TeliaSonera. Telenor Sweden and Tele2 Sweden) and Norway (TeliaSonera); for 2011. Germany (TMobjle) and Spain (Telefónica 02) and for 2011-2012, Austria (four networks: T Mobile. Mobilkom Austria, Hutchinson 3 and Orange) and France (Orange). In Italy (Telecom Italia), there is no commercial launch date.
} 
Among the circumstances conditioning the launch date of the LTE networks, the GSA document does not only deal with the market conditions. It also points towards the regulatory framework. Additionally, it touches a raw nerve in one of the basic problems for the deployment of LTE networks: spectrum availability (specifically. the $2.6 \mathrm{GHz}$ bands and the result of the digital dividend are stated). The spectrum issue is obviously not unknown to the European Commission, as in the aforementioned Communication about the broadband gap (European Commission 2006), it is stated that "the emergence of new wireless platforms particularly suited for nural areas is an interesting development. However, it requires that sufficient spectrum is made available, which in tun reinforces the importance of moving to more efficient and flexible forms of management of this scarce resource".

More interesting is the following paragraph which. despite being addressed to "traditional" broadband, could be transposed to the "advanced" broadband if it was estimated that there are no unsolvable barriers preventing, at one time or another. the arrival of high-throughput wireless technologies to the market; "The optimal mix of technologies depends on the characteristics of each particular location. The cost of technologies varies according to the number of potential users, the distance of the dwellings from the point of presence, and the presence of the backhaul. A scarcely-populated isolated area may be better off with a wireless solution and a small town with a wireline solution. Some radio solutions require a line-of-sight path which may not always be available in hilly regions. No specific technology option will offer the best connectivity in all sinuations. The optimum is often achieved by a combination of technologies and solutions. In conclusion. best solutions can only be identified at the local level. Investment and choice should be made on the basis of current availability and effective demand".

\subsubsection{Uncertainties regarding future demand}

The last sentence of the previous section transitions us into this one: the investment must be made "on the basis of ситеnt availability and effective demand".

The question can be set forth for the traditional broadband. The most recent available geographical coverage data (end of 2008) indicate that the number of "passed" households that could be connected to a fixed broadband network is up to $90 \% .{ }^{14}$ However. when comparing those coverage data with actual penetration data, it cannot be said that broadband is at present a basic service. one with the same level as, for example, telephony. It is true, though. that the number of households with a broadband connection is rapidly evolving in the European Union and has grown

\footnotetext{
${ }^{14}$ Average DSL coverage was close to $93 \%$ (up to $97 \%$ in the EU-15), with $62 \%$ of those connections having download speeds over 2 Mbps. At the national level. DSL coverage was over $88 \%$ in most countries. Only four couniries (Romania, Poland. Slovakia and Bulgaria) were still lagging behind with coverage ratios in the 65-70\% range. However, these national figures still revealed discrepancies between urban/suburban and nural areas (77\% in rural areas compared to $97.9 \%$ in urban areas). The gap between coverage in urban and rural areas was particularly signitjcant in Cyprus. Bulgaria. Romania and Slovakia but was minimal in the Benelux countries. Denmark and France. The availability of cable modems was low compared to DSL: the average national coverage rate was only about $43 \%$ at the end of 2008 , and cable was not available at all in Italy and Greece (Idate 2009).
} 
from $42 \%$ in 2007 , to $49 \%$ in 2008 and $56 \%$ in $2009 .{ }^{15}$ More complicated is the question of whether those households that have not subscribed to the service do so for reasons such as price or simply because they do not believe the service to be useful (or are unaware of the usefulness that it can provide).

But again, the problem appears in all its harshness in the case of NGA networks. It is not necessary to find other documents. The Guidelines themselves clarify in item 67 that "it should be noted that novel products or services which are not substitutable from both demand and supply side perspectives may emerge and will require broadband speeds in excess of the upper physical limits of basic broadband infrastructure". The use of the conditional tense implies that the future importance of NGA networks is currently, for the Commission itself, more of an innition than a cercainty. Believing in Say's law, the supply would end up creating the demand, one that, to support the argument for public incervention, should have an important part connected to the improvement of the productive activities and should not be limited to the most obvious leisure-related applications.

\subsection{Regarding the specific problems for the application of the Guidelines}

Returning to a less conceptual and more pragmatic perspective for the application of the Guidelines, there are also a series of issues about compliance with or the interpretation of them that could cause some conflicts.

One of the most important is the excent to which "tradicional" broadband and NGA networks can truly be differentiated. Very high speeds can be reached on copper lines. Looking at broadband from a market perspective, would it be possible to consider the different access markets as different markets?

No less important is how to guarantee the consistency between some of the measures related to the compliance of the Guidelines and the actions corresponding to the National Regulatory Authorities (NRA). Indeed, the simple differentiation into "coloured areas" implies a geographic segmentation of the markets that could not match (in fact, does not match in most cases) the borders that the NRAs have established in the market analysis they need to perform periodically. Likewise, the Guidelines also establish a series of $e x$ ante obligations to guarantee "the proportional nature" of the intervencion that could collide with the usual practice of the NRAs. This could lead to a situation where two different types of regulatory frameworks would coexist depending on the origin of the network. As stated in Sect. 2.2. in the case of the NGA networks, it is specifically stated that NRAs must be consulted. It could seem more coherent that this were the rule and that, instead of establishing extremely specific rules in the Guidelines themselves, the NRA of each country participated to define a series of conditions compatible with the specific context where they were to be applied. Finally, the Commission is reserving the right to decide whether the ex ante regulation set by the regulators is adequate as a

\footnotetext{
${ }^{15}$ Internet access and use in 2009 One person in nvo in the EU27 uses the internet daily. Eurostat News release. http:/europa.en/rapid/pressReleasesAction.do?teference=STAT/09/176\&format=HTML\&aged= $0 \&$ language $=E N \&$ guiLanguage $=e n$.
} 
"less distorting" option than resorting to public funds. Surely the NRAs will not be pleased by this prerogative.

A third aspect that could become controversial is that of the assessment of the deployment plans provided. or not. by the operators for the "near future". In some of the remarks made as a result of the public consultation, it was said that if an operator wished to paralyse a public plan. it could easily present a deployment plan backed by "evidence that would prove the credible and plausible character of the planned investment" even if its actual purpose was to delay its deployment. However. there are others who have argued the complete opposite. that private operators could "hide" their plans for later developing the network with public aid. Are these strategies probable? It is not easy to answer this question. Obviously, the release of the Guidelines is a new environment condition for the market, and the companies will take them into account for their plans. It also depends on the general regulatory framework and, as stated in the previous section. on what type of competition is encouraged. If competition in infrastructures is chosen and operators receive an important competitive advantage due to being the network holders. they will see public deployments as threats. If, on the contrary. service competition is chosen and drastic access measures to the overall deployed network are imposed, public or semi-public networks could be perceived as an opportunity.

\section{Conclusions}

The Community Guidelines for the application of State aid nules in relation to the rapid deployment of broadband networks introduce an important novelty not only for the electronic communications sector itself but also in the general scope of application of the aids. This novelty is no other than the permission granted to carry out a driving and not merely a corrective usage of public funds, naturally respecting the basic applicable rules on competition.

The affinmation refers mostly to the second type of infrastructures the Guidelines deal with; the NGA networks, the market of which, at the time the Guidelines were published in the Official Joumal, was in a truly incipient phase in most of the European Union councries. Backing this idea is the fact that the period granced to private operators to take the deployment initiative is only 3 years, a muly short period considering the enormous investment required and the uncertainties in how the demand can evolve.

Faced with this situation, what will be the response of the local and regional administrations throughout Europe? Will we witness a massive deployment of public networks? It is not easy to say, but it does not seem likely. The Guidelines, in fact. do not open any door that was expressly closed. Given the increase in the number of projects addressed to the Commission, they have tried to sort them out and clarify the conditions required. although, by doing so, the Commission has revealed that the barriers that they impose against the public deployment of NGA networks are considerably weaker than what could have been thought possible.

What should the response of these administrations be? The answer is caution and thorough analysis of both the situation they face and the options available. One must 
remember that direct actions (on the market offer side) are the most aggressive of the modalities with which a specific economic sector can be "oriented" or "driven" and generally should be the last resort in liberalised markets. This is even more the case if the option of directly deploying infrastructures is surrounded, as stated in the previous analysis, by a good number of uncertainties as regards their advisability and impact.

Therefore, it would be necessary to consider, previously and scrupulously, what other measures could contribute to reaching, if not an identical goal, at least a parallel approach to the political objective pursued. The sectorial policy has another two possible levels: intermediation actions between supply and demand (defining the market rules) and indirect accions (for example. promoting demand or applying special financial or tax conditions to the suppliers). The Commission does not complecely forget this rule because, as stated several cimes, the Guidelines themselves set forth that in the case of the grey areas (and of the white NGAs), the aids will be declared compatible, provided "there are no orher measures that cause less distortion (including the ex ante regulation) for achieving the same objectives".

In fact. the available intervention options are much more numerous, as stated by Gómez-Barroso and Feijóo (2009). Furthermore, some of them can help to achieve several objectives simultaneously. This is the case, for instance, of the indirect actions that attempt to promote demand; actions addressing part of the digital divide that depends on adoption and not access can at the same time help to eliminate the uncertainties in the behaviour of the users that burden the investment decisions of private companies. As has been shown, these uncertainties are particularly important in the case of NGA networks. Another option that offers a broad field of experimentation beforehand (because there is not enough of a cradition) is that of the public-private partnerships. The investment "under market conditions" can be attractive, particularly for the deployment of NGA networks but also for the traditional broadband and for both administrations and private companies.

In the analysis of all these options, a pragmatic vision should prevail. where the public and private sectors would be seen as cooperative and supplementary instead of antagonistic and substitutive. Following this reasoning, Frieden (2005) expresses the view that "successful ICT development typically occurs if, and only if. privace and public sector players stick to roles proven to maximise benefits". Indeed, it is not easy to determine what these roles are. In fact, there is no single recipe that is valid for any place and occasion. As stated by Horan and Schooley (2004), each community will have different economic and social requirements as regards converging networks: a single policy will probably not work for every location.

\section{References}

Analysys. (2008). Global mobile broadband: Manket potential for $3 G$ LTE (long term evolution). Repon 249-174. London. http:/www.umts-forum.org/componentoption,com_docman/hask,doc_download gid,1904/Itemid,12/.

Cave. M., Milne. C., \& Scanlan, M. (1994). Meeting thiversal senice obligations in a competitive telecommunications sector. Repon to European Commission DG IV. Luxembourg: Oftice for Official Publications of the EC. 
CMT-Isdefe. (2009). Informe final sobre los restftados del modelo de despliegue de redes FTTH/GPON en Esparia. Document ISCMTE-091856-1IL. http:/www.cmt.es/es/documentacion_de_referencia/ redes_nueva_generacion/anexos/Informe_tinal_HE_1_2008_09_MDF.pdf.

Cronin. F. J.. Parker, E. B., Colleran, E. K., \& Gold. M. A. (1991). Teleconnunuications infrasiructure and econonic growith: An analysis of causality. Telecommunications Policy, 15(6). 529-535.

Cronin, F. J., Parker, E. B., Colleran, E. K., \& Gold, M. A. (1993). Telecommunications infrastructure investment and economic development. Telecommunications Policy, 17(6), 415-430.

Dholakia. R. R., \& Harlan, B. (1994). Telecommunications and economic development: Econometric analysis of the US experience. Telecommunications Policy, 18(6), 470-477.

European Commission. (2005). State aid action plan-Less and better targeted State add: A roudhup for State aid reform 2005-2009. Communication from the Commission COM(2005) 107 inal. Brussels, 7.6.2005.

European Commission. (2006). Bridging the broadbard gap. Communication from the Commission COM (2006) 129 tinal. Brussels, 20.3.2006.

Frieden, R. (2005). Lessons from broadband development in Canada. Japan. Korea and the United States. Telecomminications Policy, 29(8), 595-613.

Gómez-Barroso, J. L., \& Feijóo, C. (2009). Policy tools for public involvement in the deployment of next genetation communications. Info-The Journal of Policy, Regulation and Strategy for Telecommunications Information and Media, 11(6). 3-13.

Gómez-Barroso, J. L., \& Pérez-Martínez. J. (2005). Public intervention in the access to advanced telecommunication services: Assessing its theoretical economic basis. Govemment Informution Quarterly, 22(3). 489-504.

Hansen, S.. Cleevely. D.. Wadsworth, S.. Bailey. H., \& Bakewell. H. (1990). Telecontnunications in rural Europe. Teleconmunications Policy, 1+(3), 207-222.

Horan, T. A., \& Schooley. B. L. (2004). Market dynainics and local policy choices for converged systems: Case sudy of integrated telecommunication design and deployment. Information Svstems Frontiers, 6(3), 205-218.

Idate. (2009). Broudbund coverage in Europe (final report. 2009 Survey. Data as of 31 December 2008). Repor 80106 for DG INFSO. http:/ec.europa.eu/information_society/eeurope/i2010/docs/ benchmarking/broadband_coverage_in_europe.pdf.

Jalava, J., \& Pohjola, M. (2002). Economic growth in the New Economy: Evidence from advanced economies. Information Economics and Policy, 14(2), 189-210.

Jalava, J.. \& Pohjola. M. (2007). ICT as a source of output and productivity growth in Finland. Telecommunications Policy, 3l(8-9), 463-472.

Koutroumpis, P. (2009). The economic impact of broadband on growth: A simultaneous approach. Telecommunications Policy, 33(9), 471-485.

Liebowitz, S. J., \& Margolis. S. E. (1994). Network externality: An uncommon tragedy. The Jotrmal of the Econonic Perspectives, 8(2), 133-150.

Madden, G., \& Savage, S. J. (1998). CEE telecommunications investment and economic growth. Information Economics and Policy, 10(2). 173-195.

OECD, Organisation for Economic Co-operation and Development. (2003). ICT and economic growth, evidence from $O E C D$ countries, industries and firms. Paris: OCDE Publications.

Ramos. S., Feijóo. C., \& Gómez-Barroso, J. L. (2009). Next generation mobile network deployment straiegies. Journal of the Institute of Telecommunications Professionals, 3(1). 13-19.

Röller. J., \& Waverman, L. (2001). Telecommunications infrastructure and economic development: a simultaneous approach. American Econonic Review, 91(4), 909-923.

Saunders, R. J.. Warford. J. J.. \& Wellenius. B. (1983). Telecommunications and economic development. London: The Johns Hopkins University Press for the World Bank.

Shleifer, A. (1998). State vetsus private ownership. Joumal of Economic Perspectives, 12(4), 133-150.

Stiglitz. J. E. (1988). Economics of the public sector. New York: W.W. Norton \& Conpany.

Timmer, M., \& Van Ark. B. (2005). Does information and communication technology drive EU-US productivity growth differentials? Oxford Economic Papers, 57(4), 693-716.

Venturini, F. (2009). The long-run impact of ICT. Enpirical Economics, 37(3), 497-515.

Wellenius, B. (1984), On the role of teleconnunications in development. Telecommunications Policy, $8(1) .59-66$. 